\title{
Long-term outcomes of school-based treatment for control of urinary schistosomiasis: a review of experience in Coast Province, Kenya
}

\author{
Charles H King \\ Center for Global Health and Diseases, Case Western Reserve University School of Medicine, 10900 Euclid Avenue, \\ Cleveland, Ohio 44106-7286, US
}

\begin{abstract}
Urinary schistosomiasis remains a significant burden for Africa and the Middle East. The success of populationbased control programs will depend on their impact, over many years, on Schistosoma haematobium reinfection and associated disease. In a multi-year (1984-1992) control program in Kenya, we examined risk for S. haematobium reinfection and late disease during and after annual school-based treatment. In this setting, long-term risk of new infection was independently associated with location, age, hematuria, and incomplete treatment, but not with sex or frequency of water contact. Thus, very local environmental features and age-related factors played an important role in $\mathrm{S}$. haematobium transmission, such that population-based control programs should optimally tailor their efforts to local conditions on a village-by-village basis. In 2001-2002, the late benefits of earlier participation in school-based antischistosomal therapy were estimated in a cohort of formerly-treated adult residents compared to never-treated adults from the same villages. Among age-matched subjects, current infection prevalence was lower among those who had received remote therapy. In addition, prevalence of bladder abnormality was lower in the treated group, who were free of severe bladder disease. Treatment of affected adults resulted in rapid resolution of infection and any detectable bladder abnormalities. We conclude that continued treatment into adulthood, as well as efforts at long-term prevention of infection (transmission control) are necessary to achieve optimal morbidity control in affected communities.
\end{abstract}

Key words: Schistosoma haematobium - Kenya - drug therapy - schistosomiasis - urinary tract

Even now, at the beginning of 2006, schistosomiasis remains one of the most significant health burdens for peoples living in vulnerable parts of the world (Chitsulo et al. 2000, van der Werf et al. 2003). Although schistosomiasis, by itself, is not often directly fatal, the $200-300$ million people who carry infection experience substantial subacute and chronic morbidities that significantly affect their health and their ability to perform the activities of their daily lives. In many settings, schistosomiasis is a disease of poverty - it frequently overlaps with infection by malaria and other chronic parasitic diseases, which contribute synergistically to the high burden of chronic illness in impoverished areas.

In reviewing the available evidence on disease burden caused by schistosomiasis, it is apparent that the World Bank/WHO Global Burden of Disease programs of the mid-1990s seriously underestimated the impact of chronic helminthic infections on individual and global health (King et al. 2005). In place of the 1.6 million DALYs attributed to schistosomiasis as its global health burden,

Financial support: Edna McConnell Clark Foundation, the Rockefeller Foundation/WHO-TDR Joint Funding Venture, the National Institutes of Health under grants AI15351, AI45473 (NIAID), and TW/ES01543 (Fogarty International Center)

E-mail:chk@cwru.edu

Received 25 May 2006

Accepted 26 June 2006 it is now estimated that from 8 up to 60 million DALYs are lost to this schistosomiasis worldwide. The extent of this upward re-evaluation indicates that there is a much greater urgency for treatment and prevention of schistosomiasis than previously acknowledged, i.e., one that is on a par with the urgency for treatment of malaria, tuberculosis, and HIV. These latter 'Global Fund' infections presently have high profiles based on their impressive contribution to early childhood mortality. Yet, based on the aggregate worldwide burden of chronic morbidity from schistosomiasis, we should still say, as Farooq pointed out over 50 years ago, "[Schistosomiasis,] this insidious and chronic disease, lacks the drama usually associated with other spectacular infections in the affected areas, and does not attract the attention that it deserves" (Farooq 1964).

We are fortunate that many countries, such as Brazil, Venezuela, Egypt, China, and the Philippines have pursued long-term national control programs for schistosomiasis. These have had a strong effect in reducing disease due to infection. However, their resources are often too limited, and complete suppression of disease has not yet been attained. In recent years, new large-scale, population-based programs have been implemented in subSaharan Africa, including national programs in Uganda, Tanzania, Zambia, Burkina Faso, Mali, and Niger under the auspices of the Schistosomiasis Control Initiative, and regional programs in Nigeria in collaboration with the Carter Center. These programs, focused on control of morbidity due to schistosomiasis, are based on annual treatment of infected or susceptible populations, using the now inexpensive oral therapy, praziquantel. For the most part, the 
implementation of these large morbidity control programs mirrors the current recommendation $\mathrm{s}$ for control put forth by the World Health Organization in 2002, as summarized in the Table.

What can we expect from the implementation of new large-scale, age-targeted schistosomiasis control programs? The real success of these national and regional control programs will depend on their long-term impact, over many years, on Schistosoma infection, reinfection, and the related impact on Schistosoma-associated disease. If treatment is age-targeted and focused on schoolbased delivery, what happens to treated students after they leave school? Also, in the face of continuing transmission, are there long-lasting benefits to be had from school-based anti-schistosomal treatment once one has left school, i.e., after childhood? and, do adults also stand to benefit in terms of regression of schistosomiasis-related morbidity when they are given treatment in expanded community-based programs?

This review summarizes the relevant experience of a long-term schistosomiasis control collaboration between the Division of Vector Borne Diseases in the Kenyan Ministry of Health, and researchers from the Case Western Reserve University in Cleveland, Ohio, US. In 1984, we jointly initiated school-based control program for $S$. haematobium in a highly-endemic, 9-village area in Coast Province, Kenya, and since that time, we have been able to follow the impact of therapy and the long-term treatment outcomes of local residents for up to 18 years. The results of these studies raise several important issues regarding the application of drug-based schistosomiasis control strategies, and suggest means for refining and improving the application of large-scale population-based control measures in affected high-risk populations.

\section{MATERIALS AND METHODS}

The results summarized in this paper are taken from previously published reports of the outcomes of the Msambweni Study, performed in the Msambweni area of Kwale District on the south coast of Kenya (King et al. 1988a,b, 1990, Muchiri et al. 1996, Ouma et al. 2005, Satayathum et al. 2006). This area is a $25 \mathrm{~km}^{2}$, 9-village area which is endemic for urinary schistosomiasis due to
S. haematobium, located about $50 \mathrm{~km}$ southwest of Mombasa, adjacent to the main Mombasa-Tanzania road. In 1984, at the outset of control, local population was 8957 , whereas in 2002 , estimated local population had grown to 16,790 . On average, over $40 \%$ of the various village populations are infected with $S$. haematobium, with untreated school-age prevalence ranging from 41 to $86 \%$. Local employment is primarily through mixed agriculture and small-scale shopkeeping, with a small minority of people working as governmental employees based at the local hospital or police station. S. haematobium transmission occurs primarily at local surface ponds formed by springs and the accumulation of seasonal rainwater which serve as habitat for Bulinus nasutus, the only intermediate host present in the immediate area (Sturrock et al. 1990, Hamburger et al. 2004).

Annual school-age treatment for S. haematobium was initiated in the Msambweni area in 1984, involving a randomized controlled trial of praziquantel vs metrifonate therapy (King et al. 1988, 1990, 1991). After three years, school-based treatment was shifted to sole use of praziquantel, and regular treatment continued on an annual basis until 1992 (King et al. 2000, Satayathum et al. 2006). Screening and regular treatment resumed in 1999, with the implementation of community-based programs for diagnosis and follow-up (King et al. 2004, Ouma et al. 2005). It was during the course of these community surveys that many of the late outcomes of previous school-age treatment were assessed, and the benefits of current therapy for adult disease were measured.

Ethics - The studies reported here were all performed according to the standards outlined under the Declaration of Helsinki (1975, and as revised 1983). The research was performed after informed subject consent under protocols approved by the Ethical Review Committee of the Kenya Medical Research Institute (Nairobi), and by the Human Investigation Review Board of University Hospitals of Cleveland, Ohio, US.

\section{RESULTS}

Rationale for school-based approach - The initial decision to implement school-based drug treatment for $S$.

TABLE

Current World Health Organization recommendations for community based control of schistosomiasis-associated morbidity in endemic areas (WHO 2002)

\begin{tabular}{lll}
\hline Community category & $\begin{array}{l}\text { Intervention in schools } \\
\text { (enrolled and non-enrolled children) }\end{array}$ & $\begin{array}{l}\text { Health Services and } \\
\text { community-based intervention }\end{array}$ \\
\hline I. High prevalence & $\begin{array}{l}\text { Targeted treatment of school-age children, } \\
\text { once a year }\end{array}$ & $\begin{array}{l}\text { Access to PZQ for passive case treatment } \\
\text { community-directed treatment for high-risk } \\
\text { groups recommended }\end{array}$ \\
II. Moderate prevalence & $\begin{array}{l}\text { Targeted treatment of school-age children, } \\
\text { once every 2 years }\end{array}$ & $\begin{array}{l}\text { Access to PZQ for passive case treatment } \\
\text { III. Low prevalence }\end{array}$ \\
$\begin{array}{l}\text { Targeted treatment of school-age children } \\
\text { twice during primary schooling } \\
\text { (once on entry, again on leaving) }\end{array}$ & Access to PZQ for passive case treatment \\
\hline
\end{tabular}

Treatment strategies should always be accompanied by efforts to improve water supply and sanitation; PZQ: praziquantel; $a$ : can be done on presumptive grounds, according to diagnostic algorithms adapted to the endemic situation. 
haematobium was based on the following epidemiological features of urinary schistosomiasis: (i) transmission is often highly focal; (ii) prevalence and intensity of infection vary significantly with age; (iii) morbidity of infection varies with age; (iv) infection intensity not normally distributed, with clustering of heavy infection among children of school-age; and (v) signs of early disease are correlated with greater intensity of infection (see Fig. 1). This strategy grew out of earlier observations on the local distribution of $S$. haematobium infection and disease in Coast Province (Warren et al. 1979, King et al. 1988), and more general considerations of the dynamics of parasite transmission and of the known heterogeneity of infectious burden and of parasite transmission potential (Anderson \& May 1982, Warren 1982, Jordan 1985). In particular, consideration was given to the possibility that broad treatment coverage amongst the most heavily infected segment of the population (i.e., schoolchildren) might, in fact, reduce overall community transmission by sufficiently suppressing parasite worm burden to a transmission 'break point', below which successful parasite mating could no longer efficiently occur (MacDonald 1965).

Implementation of school-based control began in 1984, and included screening and treatment of all available school-age children, whether in school or non-schoolgoers, in 9 communities of the Msambweni area on the south coast of Kenya. The area selected for study was chosen on the basis of its compact distribution with a

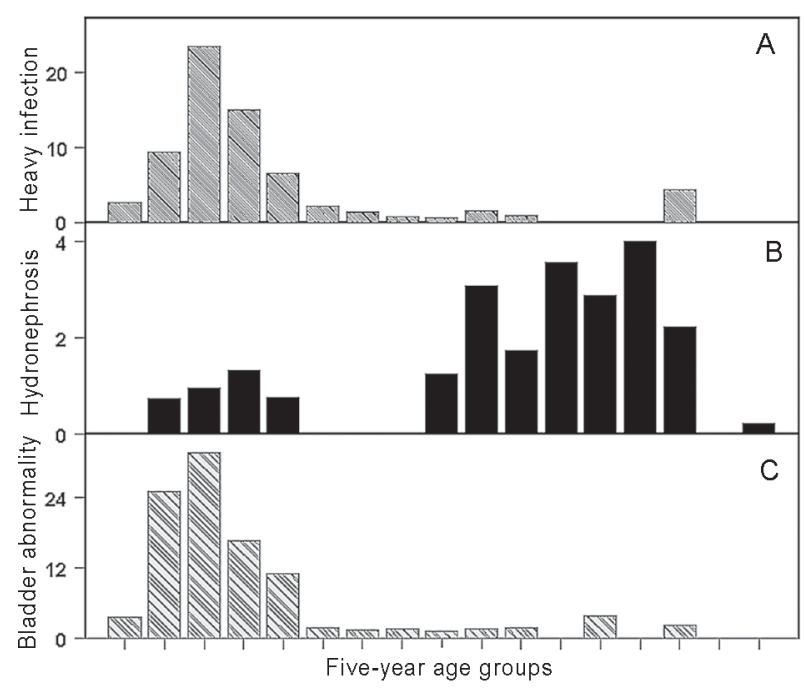

Fig. 1: age profile of Schistosoma haematobium infection intensity and associated disease in the highly-endemic Msambweni area of Coast Province, Kenya, prior to treatment in 2000-2001. A: indicates the percent prevalence of heavy infections $(\geq 400 \mathrm{eggs} /$ $10 \mathrm{ml}$ urine) for each 5-year age group (0-4 yr, 5-9yr, etc.); B: indicates the prevalence of hydronephrosis; $\mathrm{C}$ : indicates the prevalence of significant bladder thickening or irregularity for the same population. Significant grouping of high-intensity infection and structural urinary tract disease is seen in the youngest age categories. A separate grouping of obstructive urinary tract disease (hydronephrosis) is noted in age groups $>50 \mathrm{yr}$ (from King et al. 2004, with permission). surrounding buffer zone of sugar plantations, which limited cross-transmission mediated by outside untreated populations (King et al. 1988a, b). Annual surveys monitored S. haematobium infection prevalence and intensity, along with its associated morbidity (hematuria, ultrasound abnormalities) in the targeted age groups. In addition, water use and water contact were monitored, along with bulinid snail abundance and infection levels (el Kholy et al. 1989, Sturrock et al. 1990, Muchiri et al. 1996). The annual treatment program (with either metrifonate or praziquantel, Fig. 2) resulted in significant reductions in infection prevalence and intensity for all targeted age groups (Fig. 3).

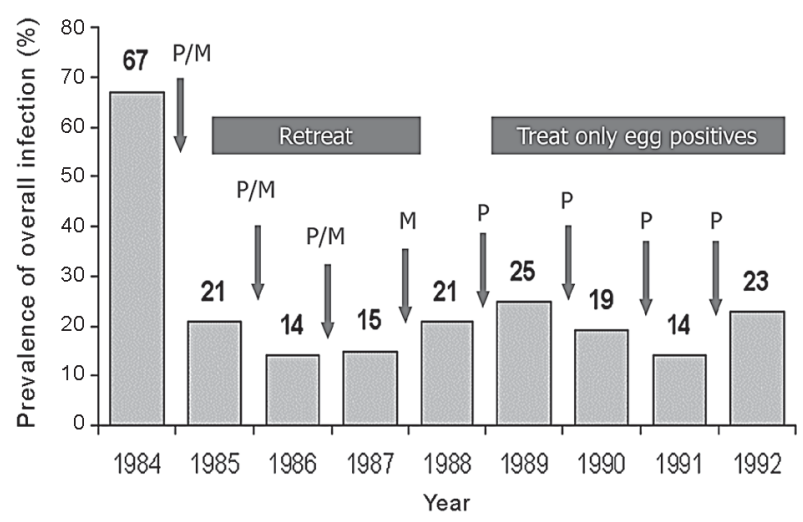

Fig. 2: schematic of the Msambweni Project school-based treatment program. After initial surveys in 1984, when pre-treatment prevalence was $67 \%$ (left-hand bar), randomized therapy with either praziquantel $(\mathrm{P})$ or metrifonate $(\mathrm{M})$ was implemented for all children found to be infected by urine filtration parasitology examination. The assigned drug treatment was continued for 2 more years (arrows), followed by a 'consolidation' treatment with a single does of metrifonate in 1987. School-age group Schistosoma haematobium prevalence is indicated by the grey bars for each year. Regular treatment with praziquantel (only) was then implemented for all infected subjects for the years between 1988 and 1992 (see King et al. 1991, Satayathum et al. 2006).

The impact of school-based treatment on S. haematobium-associated morbidity was significant - Hematuria and proteinuria prevalence among targeted schoolchildren was reduced from $50-60 \%$ down to $18-20 \%$ by the third year of the program (Muchiri et al. 1996). Structural urinary tract abnormalities detected by ultrasound were significantly improved after one year (King et al. 1990), and persistent abnormalities continued to improve in successive years (King et al. 1992).

The impact of school-based treatment on transmission was quite variable - Although the initial phase of the program was estimated to effectively treat $86 \%$ of all school-age children, S. haematobium transmission was only reduced in some but not all villages. Transmission was estimated by two means, annual prevalence of infection among younger 4 yr-old children who aged into the school age group each year, and by annual incidence (negative-to-positive conversion of urine parasitology 

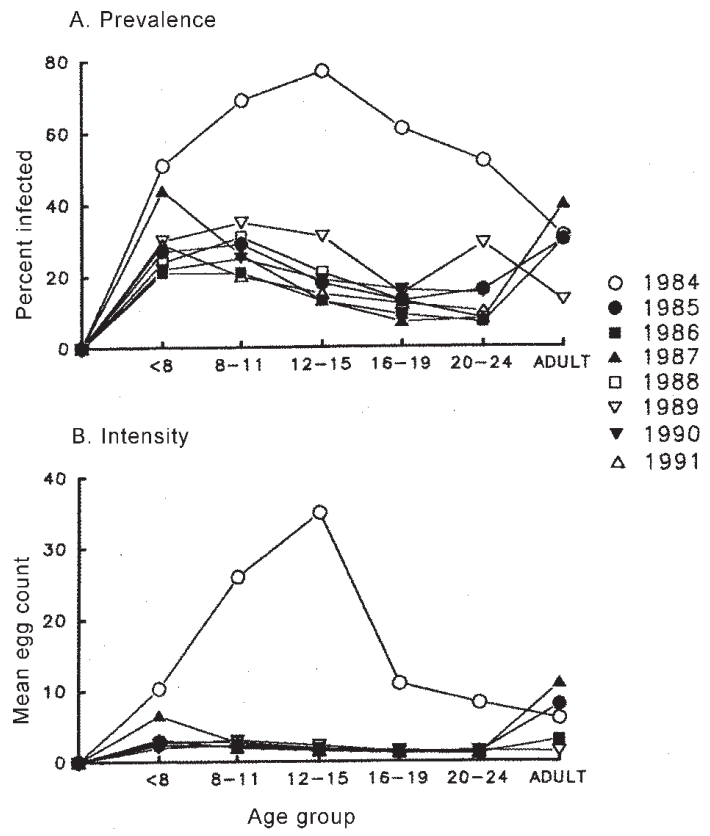

Fig. 3: age profile of Schistosoma haematobium infection prevalence (A) and geometric mean intensity (B) for the school-age groups participating in the Msambweni Project between 1984 and 1992. Significant decreases were noted in both intensity and prevalence for all school-age groups under the age of $20 \mathrm{yr}$ (from King et al. 1991, with permission).

examination) for the school-age group each year. Our preliminary analysis indicated significant differences in risk for new infection among schools and among study villages (Muchiri et al. 1996). In particular, villages without any piped water access maintained a high level of infection and reinfection throughout the study period.

A recent, more extensive multivariable analysis using Cox proportional hazard technique indicates that, independent of other factors, it was location of residence, subject age, the presence of pretreatment hematuria, and the lack of complete treatment that were significantly associated for risk of new infection during the control program. By contrast, subject's sex and frequency of water contact were not significant independent predictors of infection risk (Satayathum et al. 2006). In general, villages with the highest initial prevalences of infection were also at highest risk of continuing transmission, with the median time to reinfection being 2 years in the worst village and $>8$ years in the lowest risk villages.

Our subsequent mapping of community households and snail activity at water contact sites has indicated substantial heterogeneity in the site-by-site levels of infection risk (Fig. 4, see Hamburger et al. 2004) as well as substantial clustering of human infection intensity around certain high-risk water contact sites (Fig. 5, see Clennon et al. 2004).

The long-term impact of previous participation in school-based treatment programs was recently assessed by community-based follow-up of Msambweni area adults

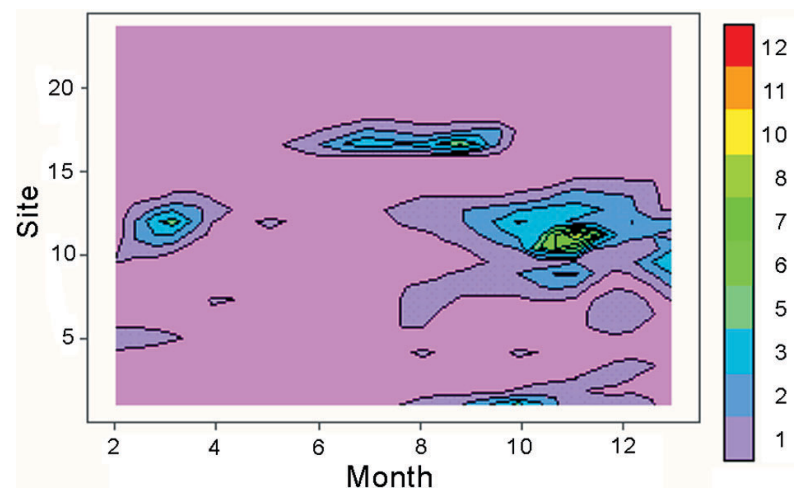

Fig. 4: plot indicating the numbers of Schistosoma haematobiumshedding bulinid snails (BAFHC) over 12 months time in 20 monitored water contact sites across the Msambweni study area in 2000. Significant site-to-site variation was noted in timing and abundance of transmitting snails. Although overall snail numbers and prevalence of infected snails was tied to seasonal rainfall (see Kariuki et al. 2004), very local factors appeared to significantly limit the presence of shedding snails in some locations (see Hamburger et al. 2004).

who had participated as children in the treatment programs in the 1980s and early 1990s (Ouma et al. 2005). When examined, these previously-treated adults were found to have infection prevalence that was significantly lower (22 vs 33\%) than age-matched adults who had not been treated, although the number of individuals with heavy infection was not significantly different between these two groups ( 2.3 vs $3 \%$, respectively). In terms of morbidity, the remote prior treatment was associated with significantly lower rates of current hematuria and bladder abnormalities detected on ultrasound, and the previously treated adults were noted to have a complete absence of severe-grade bladder disease (Ouma et al. 2005). Among those who had been previously treated, those adults who had had 3 or more treatments during their school years had significantly lower risk of present infection and bladder disease, and those who were last treated later in their schooling also had a reduced risk of current infection and hematuria (Ouma et al. 2005). Our unpublished results after treatment of these adults indicate that they responded well to treatment, both in terms of eradication of infection ( $85 \%$ clearance) and in terms of rapid regression of bladder abnormalities.

\section{DISCUSSION}

The experience of the multi-year school-based Msambweni treatment program for urinary schistosomiasis suggests several strengths and limitations to the current WHO guidelines for targeted control of schistosomiasis-associated morbidity. The currently recommended strategies for low- medium-and high-prevalence areas (Table) are primarily focused on treatment of school-age children, but are not well defined for treatment of adult residents in the same vulnerable areas.

Can school-age treatment of endemic areas result in significant morbidity control? The answer is decidedly, yes. Our experience and the results of other similar treat- 


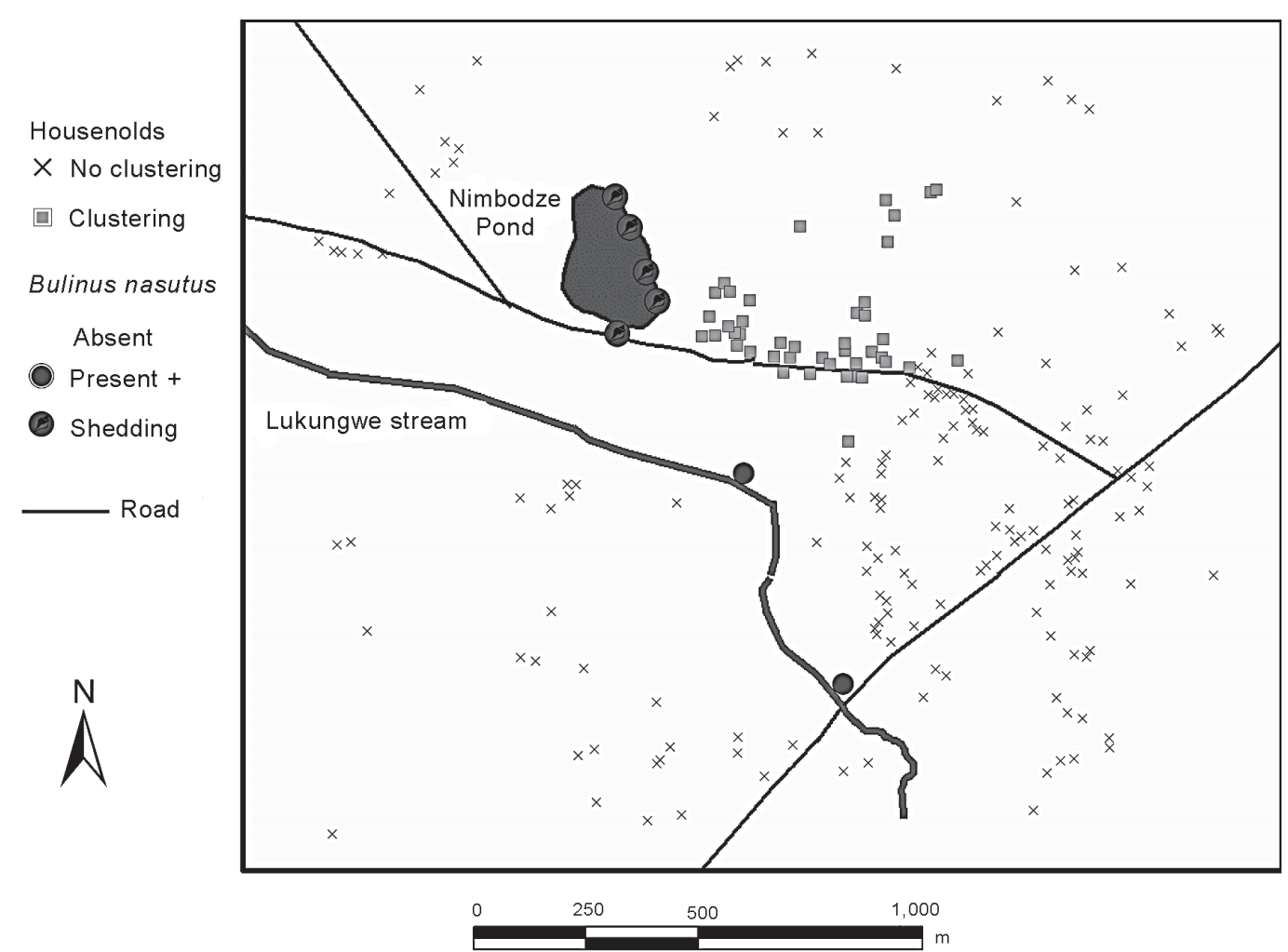

Fig. 5: analysis of significant spatial clustering of high-intensity infection in the westernmost village of the Msambweni study area. There was a significant clustering effect around the specific sites on Nimbodze pond found to have snails shedding cercariae of Schistosoma haematobium. The influential radius of the clustering effect is between 200 and $1000 \mathrm{~m}$ from these transmission sites, but, not shown here, the significant distance factor varies according to subject age group studied, growing larger for older age groups (see Clennon et al. 2004).

ment programs (Savioli et al. 1990, Hatz et al. 1998) indicate that regular treatment of school-age children can significantly reduce the levels of clinical and occult morbidity in S. haematobium-affected populations. Our longterm follow-up studies (Ouma et al. 2005) now indicate that some (but not all) of the benefits of school-age therapy can persist into adulthood, and that more than 2 treatments during childhood can enhance the late benefits observed after having participated in a treatment campaign as a schoolchild.

Does control of infection intensity prevent morbidity? There is a loose correlation between intensity of schistosome infection and risk for morbidity (Warren et al. 1979), and this association has been used to emphasize the need to treat school-age children, who harbor the highest levels of infection (Fig. 1). Nevertheless, there is only a loose association between intensity and morbidity - recent studies indicate that, independent of infection intensity, individual profiles of immune responses to parasite antigens are much better predictors of risk of bladder disease in S. haematobium infection (Wamachi et al. 2004). Thus, some older individuals without heavy infection remain at significant risk for $S$. haematobium-associated disease if they are left untreated. In other respects, it may be duration of infection (or for long-term residents, age at diagnosis) that determines risk of structural urinary tract disease in endemic areas (e.g. hydronephrosis over age
50 in Fig. 1; see also King et al. 1988a, b, Hodder et al. 2000).

Should adults in high prevalence areas be treated? Based on the evidence above, and our unpublished experience in obtaining regression of bladder and kidney disease after treatment of adult age groups, the answer should be - yes.

Can school-age treatment affect transmission? Miguel and Kremer (2004) have evaluated the potential economic 'externalities' or side-benefits of large anti-helminth treatment programs. One desirable goal that could reasonably be obtained is to reduce community-wide parasite transmission, such that all residents ultimately benefit from the population-based treatment program. As expected, transmission suppression requires high levels of participation by eligible residents. MacDonald's original 1965 analysis of schistosomiasis transmission (MacDonald 1965) suggested that there is the potential to reach a critical 'breakpoint' in environmental transmission in endemic communities that can obviate the need for complete eradication of infection. Our experience indicates that aggressive targeted school-age treatment can suppress transmission in some, but not all S. haematobium infected communities. Why should this be so? Woolhouse and colleagues have pointed out the strong stabilizing effects of community webs of transmission, whereby one individual uses multiple water sites, and a single untreated person can main- 
tain local transmission for an indefinite period (Woolhouse et al. 1991, 1997, 1998).

We have examined extended community models of multiple villages interacting with multiple water contact sites (Fig. 6, Gurarie \& King 2005), and find that the interconnected web of transmission serves to perpetuate infection across large areas. In such a setting, universal age-based treatment is superior to focusing on individual high-prevalence villages. Despite the effects of inter-connectedness, such a school age-based strategy can economically stop infection in a low-transmission environment, and should achieve cost-effective reduction in community-wide levels of infection intensity in the high-transmission areas (Gurarie \& King 2005). Nevertheless, transmission control in high risk areas clearly require additional approaches to achieve eradication.

Where do we go from here? The long-term success of schistosomiasis control programs will depend on their sustainable impact on morbidity prevalence, and ultimately their impact on infection prevalence. Given the distinction, in some cases, between infection intensity and morbidity risk (Wamachi et al. 2004), even light infection imposes risk of serious disease. Given the association between schistosome infection and anemia and other disability-related outcomes (King et al. 2005), infection at any level may impose a significant burden on local health. If so, then prevention of infection should be the ultimate goal of morbidity control.
If, in the next phase of control, S. haematobium infection is to be prevented, it is important first to recognize that local village-scale environmental features and agerelated factors both play predominant roles in perpetuating $S$. haematobium transmission (Satayathum et al. 2006). In large population-based control programs, treatment allocation strategies may need to be tailored to local conditions on a village-by-village basis. Without modification of transmission factors, whether potentially by snail control, habitat modification, or water and sanitation programs, even mass treatment may only result in a new, lower equilibrium of transmission and low-level infection for an indefinite future (Gurarie \& King 2005). Given the potential for community and donor fatigue in large projects, we must expect that without changes in transmission potential, even multiple years of annual treatments will not be enough for adequate schistosomiasis control in many areas.

The next level of control will need to coordinate with efforts at multiparasite 'deworming' (to reduce delivery costs) and with efforts at infrastructure development and poverty reduction to break the local cycle of schistosome transmission in high risk areas (Utzinger et al. 2003). It is increasingly apparent that schistosomiasis control should be seen as a part of a comprehensive plan for reduction of overall disease burden in affected areas, and should remain a priority for regional and national health programs in all endemic areas.

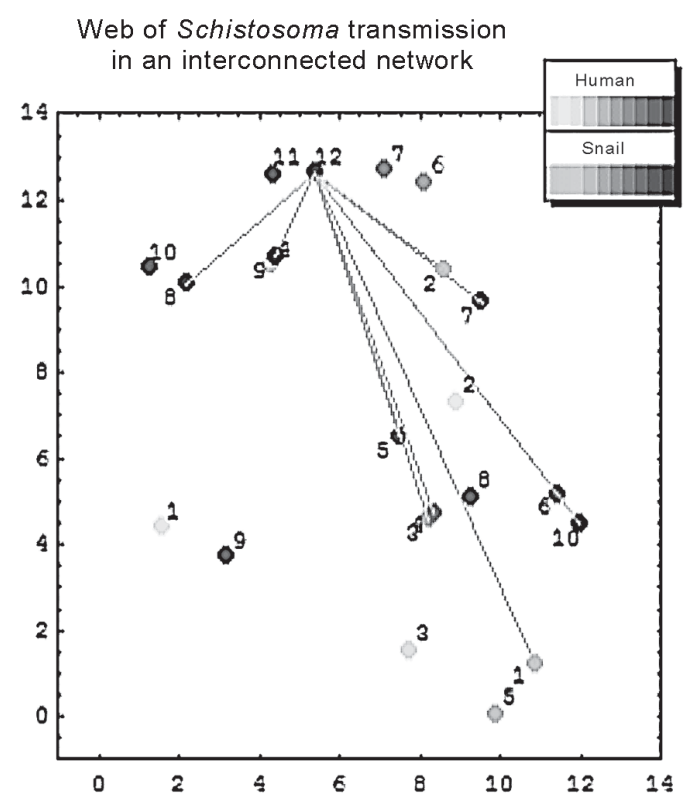

Gurarie \& King, Parasitology 2005
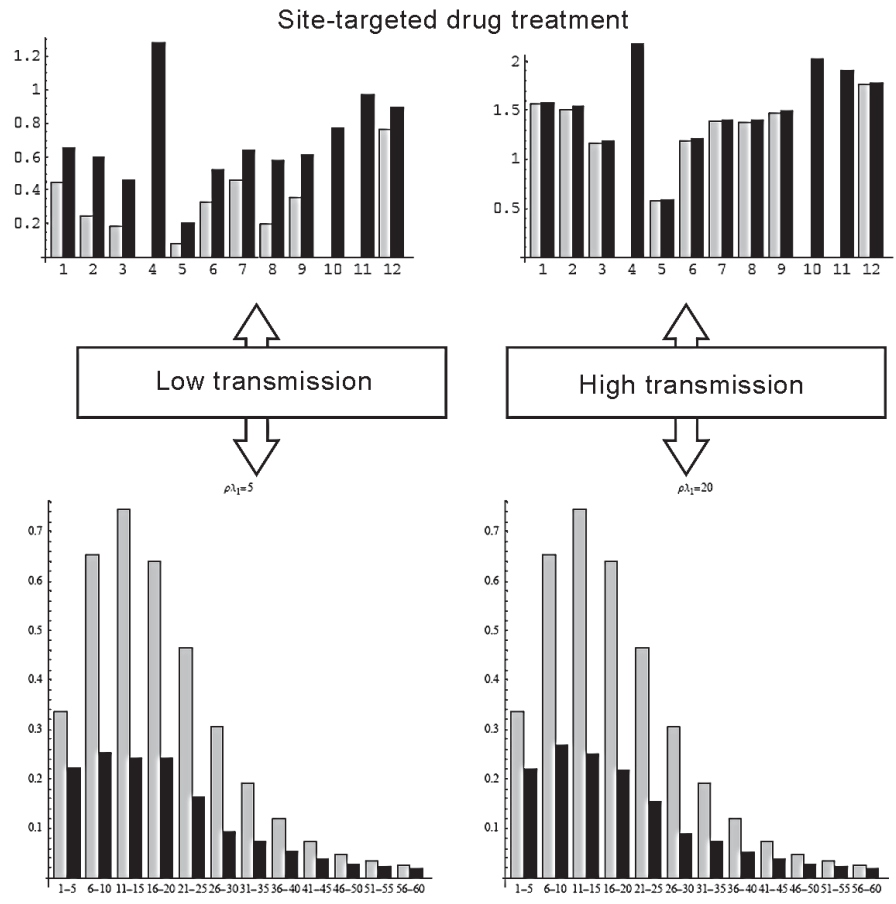

Age-targeted drug treatment

Fig. 6: simulated impact of different population-based drug treatment programs in a distributed transmission environment of dispersed but interconnected human communities and intermediate host snail habitats (left panel). Based on the modeling of Gurarie and King (2005), the right-hand panels indicate the effects of targeted site-specific (upper panels) or age-specific (lower panels) treatment campaigns. Bars indicate average worm burdens before (black bars upper panels, grey bars lower panels) and after (gray bars, upper; black bars, lower) initiation of treatment with each treatment strategy. Outcomes for both low-transmission and high-transmission areas are indicated by the central labels. 


\section{ACKNOWLEDGMENTS}

To all my Kenyan and US colleagues who have worked over the last two decades to make the Msambweni project a success. In particular, I thank my project co-leader Dr Eric Muchiri, Head of the Division of Vector Borne Diseases of the Ministry of Health, Kenya; Dr John Ouma, past Head of DVBD; Dr Davy Koech, Director of the Kenya Medical Research Institute; Mr Peter Mungai, Field Coordinator of the Msambweni Project; Dr Adel Mahmoud, former Chairman of Medicine, Case Western Reserve University, Dr David Gurarie of the CWRU Department of Mathematics, and Sudtida Satayathum of the Department of Epidemiology and Biostatistics at CWRU for their extensive contributions to the studies described in this paper.

\section{REFERENCES}

Anderson RM, May RM 1982. Population dynamics of human helminth infections: control by chemotherapy. Nature 297: 557-563.

Chitsulo L, Engels D, Montresor A, Savioli L 2000. The global status of schistosomiasis and its control. Acta Trop 77: $41-51$.

Clennon JA, King CH, Muchiri EM, Kariuki HC, Ouma JH, Mungai P, Kitron U 2004. Spatial patterns of urinary schistosomiasis infection in a highly-endemic area of coastal Kenya. Am J Trop Med Hyg 70: 443-448.

el Kholy H, Arap Siongok TK, Koech D, Sturrock RF, Houser H, King CH, Mahmoud AAF 1989. Effects of borehole wells on water utilization in Schistosoma haematobium endemic communities in Coast Province, Kenya. Am J Trop Med Hyg 41: 212-219.

Farooq M 1964. Medical and economic importance of schistosomiasis. Am J Trop Med Hyg 67: 105-112.

Gurarie D, King CH 2005. Heterogeneous model of schistosomiasis transmission and long-term control: the combined influence of spatial variation and age-dependent factors on optimal allocation of drug therapy. Parasitology 130: 4965.

Hamburger J, Hoffman O, Kariuki HC, Muchiri EM, Ouma JH, Koech DK, Sturrock RF, King CH 2004. Large-scale, polymerase chain reaction-based surveillance of Schistosoma haematobium DNA in snails from transmission sites in coastal Kenya: A new tool for studying the dynamics of snail infection. Am J Trop Med Hyg 71: 765-773.

Hatz CF, Vennervald BJ, Nkulila T, Vounatsou P, Kombe Y, Mayombana C, Mshinda H, Tanner M 1998. Evolution of Schistosoma haematobium-related pathology over 24 months after treatment with praziquantel among school children in southeastern Tanzania. Am J Trop Med Hyg 59: 775-781.

Hodder SL, Mahmoud AAF, Sorenson K, Weinert DM, Stein RL, Ouma JH, Koech D, King CH 2000. Predisposition to urinary tract epithelial metaplasia in Schistosoma haematobium infection. Am J Trop Med Hyg 63: 133-138.

Jordan P 1985. Schistosomiasis: The St. Lucia Project, Cambridge University Press, Cambridge.

Kariuki HC, Clennon JA, Brady MS, Kitron U, Sturrock RF, Ouma JH, Ndzovu M, Mungai P, Hoffman O, Hamburger J, Pellegrini C, Muchiri EM, King CH 2004. Distribution patterns and cercarial shedding of Bulinus nasutus and other snails in the Msambweni area, Coast Province, Kenya. Am
J Trop Med Hyg 70: 449-456.

King CH, Blanton RE, Muchiri EM, Ouma JH, Kariuki HC, Mungai P, Magak P, Kadzo H, Ireri E, Koech D 2004. Low heritable component of risk for infection intensity and infection-associated disease in urinary schistosomiasis among Wadigo village populations in Coast Province, Kenya. Am J Trop Med Hyg 70: 57-62.

King CH, Dickman K, Tisch DJ 2005. Reassessment of the cost of chronic helmintic infection: a meta-analysis of disability-related outcomes in endemic schistosomiasis. Lancet 365: 1561-1569.

King CH, Keating CE, Muruka JF, Ouma JH, Houser H, Siongok TK, Mahmoud AAF 1988a. Urinary tract morbidity in schistosomiasis haematobia: associations with age and intensity of infection in an endemic area of Coast Province, Kenya. Am J Trop Med Hyg 39: 361-368.

King CH, Lombardi G, Lombardi C, Greenblatt R, Hodder S, Kinyanjui H, Ouma J, Odiambo O, Bryan PJ, Muruka J, Magak P, Weinert D, Mackay W, Ransohoff D, Houser H, Koech D, Siongok TK, Mahmoud AAF 1988b. Chemotherapy-based control of schistosomiasis haematobia. I. Metrifonate versus praziquantel in control of intensity and prevalence of infection. Am J Trop Med Hyg 39: 295-305.

King CH, Lombardi G, Lombardi C, Greenblatt R, Hodder S, Kinyanjui H, Ouma J, Odiambo O,. Bryan PJ, Muruka J, Magak P, Weinert D, Mackay W, Ransohoff D, Houser H, Koech D, Siongok TK, Mahmoud AAF 1990. Chemotherapy-based control of schistosomiasis haematobia. II. Metrifonate vs. praziquantel in control of infection-associated morbidity. Am J Trop Med Hyg 42: 587-595.

King CH, Muchiri EM, Ouma JH, Koech D 1991. Chemotherapy-based control of schistosomiasis haematobia. IV. Impact of repeated annual chemotherapy on prevalence and intensity of Schistosoma haematobium infection in an endemic area of Kenya. Am J Trop Med Hyg 45: 498-508.

King CH, Muchiri EM, Ouma JH 1992. Age-targeted chemotherapy for control of urinary schistosomiasis in endemic populations. Mem Inst Oswaldo Cruz 87(Suppl. 4): 203210.

King CH, Muchiri EM, Ouma JH 2000. Evidence against rapid emergence of praziquantel resistance in Schistosoma haematobium, Kenya. Emerg Infect Dis 6: 585-594.

MacDonald G 1965. The dynamics of helminth infections, with special reference to schistosomes. Trans $R$ Soc Trop Med Hyg 59: 489-506.

Miguel E, Kremer M 2004. Worms: Identifying impacts on education and health in the presence of treatment externalities. Econometrica 72: 159-217.

Muchiri EM, Ouma JH, King CH 1996. Dynamics and control of Schistosoma haematobium transmission in Kenya: an overview of the Msambweni Project. Am J Trop Med Hyg 55(Suppl.): 127-134.

Ouma JH, King CH, Muchiri EM, Mungai P, Koech DK, Ireri E, Magak P, Kadzo H 2005. Late benefits 10-18 years after drug therapy for infection with Schistosoma haematobium in Kwale District, Coast Province, Kenya. Am J Trop Med Hyg 73: 359-364.

Satayathum SA, Muchiri EM, Ouma JH, Whalen CC, King CH 2006. Factors affecting infection or reinfection with Schis- 
tosoma haematobium in coastal Kenya: Survival analysis during a nine-year, school-based treatment program. Am J Trop Med Hyg (in press).

Savioli S, Hatz C, Dixon H, Kisumku UM, Mott KE 1990. Control of morbidity due to Schistosoma haematobium on Pemba Island: egg excretion and hematuria as indicators of infection. Am J Trop Med Hyg 43: 289-295.

Sturrock RF, Kinyanjui H, Thiongo FW, Tosha S, Ouma JH, King CH, Koech D, Siongok TK, Mahmoud AAF 1990. Chemotherapy-based control of schistosomiasis haematobia. 3. Snail studies monitoring the effect of chemotherapy on transmission in the Msambweni area, Kenya. Trans R Soc Trop Med Hyg 84: 257-261.

Utzinger J, Bergquist R, Xiao SH, Singer BH, Tanner M 2003. Sustainable schistosomiasis control - the way forward. Lancet 362: 1932-1934.

van der Werf MJ, de Vlas SJ, Brooker S, Looman CW, Nagelkerke NJ, Habbema JD, Engels D 2003. Quantification of clinical morbidity associated with schistosome infection in subSaharan Africa. Acta Trop 86: 125-139.

Wamachi AN, Mayadev JS, Mungai PL, Magak PL, Ouma JH, Magambo JK, Muchiri EM, Koech DK, King CH, King CL 2004. Increased ratio of tumor necrosis factor-alpha to interleukin-10 production is associated with Schistosoma haematobium-induced urinary-tract morbidity. J Infect Dis 190: 2020-2030.

Warren KS 1982. Selective primary health care: strategies for control of disease in the developing world. I. Schistosomiasis. Rev Infect Dis 4: 715-726.

Warren KS, Mahmoud AAF, Muruka JF, Whittaker LR, Ouma JH, Arap Siongok TK 1979. Schistosomiasis haematobia in Coast Province, Kenya. Relationship between egg output and morbidity. Am J Trop Med Hyg 28: 864-870.

WHO 2002. Prevention and control of schistosomiasis and soiltransmitted helminthiasis: Report of a WHO expert committee. Technical Report Series 912. Geneva, p. 2-5.

Woolhouse ME, Dye C, Etard JF, Smith T, Charlwood JD, Garnett GP, Hagan P, Hii JL, Ndhlovu PD, Quinnell RJ, Watts CH, Chandiwana SK, Anderson RM 1997. Heterogeneities in the transmission of infectious agents: implications for the design of control programs. Proc Natl Acad Sci USA 94: 338-342.

Woolhouse ME, Etard JF, Dietz K, Ndhlovu PD, Chandiwana SK1998. Heterogeneities in schistosome transmission dynamics and control. Parasitology 117: 475-482.

Woolhouse ME, Watts CH, Chandiwana SK 1991. Heterogeneities in transmission rates and the epidemiology of schistosome infection. Proc R Soc Lond B Biol Sci 245: 109-114. 